\title{
Artritis séptica causada por Kingella kingae en pediatría
}

\author{
Septic arthritis caused by Kingella kingae in children
}

\author{
Dra. María Isabel Garzón ${ }^{,}$Bioq. Daniela Verónica Hernández $z^{b}$ y Dr. Juan Pablo Caeiro ${ }^{a}$ \\ Colaboradores: Lic. Natalia Soledad Avilés ${ }^{b}$ Dra. Lorena Sartoric y Lic. Sebastián Caliva Agüero ${ }^{b}$
}

\begin{abstract}
RESUMEN
Introducción. Aproximadamente un $50 \%$ de los casos de artritis bacteriana ocurre en la infancia. En la actualidad, se considera Kingella kingae como un patógeno emergente.

Caso clínico. Varón de 10 meses que consulta por fiebre y dolor en la rodilla. Se realizó artrocentesis. La muestra se sembró en frasco de hemocultivo. Se identificó Kingella kingae. Recibió tratamiento con ampicilina por 14 días.

Discusión. La patogenia de la enfermedad articular causada por Kingella kingae comienza con la colonización de la faringe posterior. El aislamiento en los medios de cultivo sólidos puede ser difícil.

Conclusión. Se destaca la necesidad de tener en cuenta este patógeno y de utilizar, en forma rutinaria, frascos de hemocultivo para el procesamiento de las muestras de líquido sinovial.
\end{abstract}

Palabras clave: artritis, Kingella kingae, medios de cultivo.

\begin{abstract}
Introduction. Approximately $50 \%$ of cases of bacterial arthritis occur in childhood. Currently Kingella kingae is considered as an emerging pathogen.

Clinical case. A ten month old male patient presented joint immobility in right knee. Arthrocentesis was performed. Kingella kingae was identified. He received treatment with ampiciline for 14 days.

Discussion. This pathogen colonizes the posterior pharynx. Isolation in solid culture media may be difficult.

Conclusion. It is essential to consider this pathogen when septic arthritis is suspected, and to routinely use blood culture bottles for processing samples of synovial fluid.

Key words: arthritis, Kingella kingae, culture media.
\end{abstract}

http: / / dx.doi.org/10.5546/aap.2015.e120

\section{INTRODUCCIÓN}

La artritis bacteriana es más frecuente en la infancia que en otros períodos de la vida y se caracteriza por la invasión del espacio articular por diversos microorganismos.

a. Servicio de Infectología.

b. Laboratorio de Microbiología.

c. Servicio de Pediatría.

Hospital Privado de Córdoba.

Correspondencia:

Dra. María Isabel Garzón: mariaisabelgarzon@gmail.com

Conflicto de intereses: ninguno que declarar.

Recibido: 8-10-2014

Aceptado: 5-11-2014
Aproximadamente un $50 \%$ de los casos ocurren en personas menores de 20 años. La incidencia de la artritis bacteriana en niños es de 5 a 37 casos por 100000 . Los niños menores de 3 años se ven afectados con más frecuencia. Suelen ser monoarticulares y perjudican principalmente las articulaciones de las extremidades, como la cadera, el tobillo y la rodilla. Su relevancia radica en la asociación de un manejo difícil, desde el punto de vista médico quirúrgico, con numerosas complicaciones. Por esta razón, esta patología requiere el reconocimiento y el tratamiento inmediato, como así también un abordaje multidisciplinario. Debido a que el retraso en la terapia se ha asociado con secuelas a largo plazo, el tratamiento de los lactantes y los niños con artritis bacteriana sospechada debe comenzar inmediatamente después de que se obtuvieron cultivos de sangre y de líquido sinovial.

Las bacterias aisladas con más frecuencia en los niños con artritis bacteriana varían dependiendo de la edad y el estado de vacunación, como así también de la región geográfica en la que se encuentren. La terapia empírica en los niños mayores de tres meses debe orientarse hacia S. aureus, el germen más frecuente en este grupo etario, seguido de otros organismos Grampositivos (estreptococos del grupo A, Streptococcus pneumoniae). Con respecto al grupo de Gramnegativos, debemos considerar que, en las últimas dos décadas, la vacunación sistémica contra Haemophilus influenzae ha modificado el patrón de infección ósea y es, en la actualidad, K. kingae el germen Gram-negativo implicado con más frecuencia.

El género Kingella está compuesto principalmente por tres especies: K. kingae, que coloniza el tracto respiratorio superior, sobre todo, en niños pequeños; K. oralis, que se encuentra en la cavidad oral; y K. denitrificans, cuyo hábitat es desconocido. Pertenece al grupo HACEK (Haemophilus, Aggregatibacter, Cardiobacterium, Eikenella corrodens, Kingella kingae), cuyas características son la exigencia en el cultivo y la facilidad de infectar válvulas cardíacas. ${ }^{1}$ 
Actualmente, se considera Kingella kingae como un patógeno emergente, no solo debido a un posible cambio epidemiológico por aumento de las infecciones, sino también debido a un mejor conocimiento de la bacteria y mejores técnicas de diagnóstico microbiológico. La dificultad de asilamiento con métodos convencionales y su presentación clínica inespecífica puede hacer que no se identifique o se confunda, por lo que la sospecha clínica y la orientación diagnóstica son claves para un correcto manejo.

\section{CASO CLÍNICO}

Varón de 10 meses sin antecedentes perinatales ni patológicos de importancia, que acude a la guardia con un cuadro febril de $48 \mathrm{~h}$ de evolución, edema, rubor y limitación funcional de rodilla derecha en las últimas horas. Cinco días antes de la consulta, presentó infección de la vía aérea superior. Los análisis de sangre mostraron 18600 glóbulos blancos con fórmula desviada a la izquierda; hemoglobina: 9,5 g/ dl; hematocrito: $27,8 \%$; plaquetas: $462000 \mathrm{~K} / \mathrm{ul}$; y proteína $C$ reactiva (PCR): $4,61 \mathrm{mg} / \mathrm{dl}$. Se tomaron dos muestras de hemocultivo. Una ecografía de la articulación evidenció moderada cantidad de líquido en la articulación sinovial de la rodilla derecha. Se realizó artrocentesis, y se extrajeron $10 \mathrm{ml}$ de líquido purulento. En la coloración de Gram, no se observaron gérmenes. Se inició tratamiento empírico con cefazolina de $100 \mathrm{mg} / \mathrm{kg}$ / día. La muestra se sembró en agar Columbia con $5 \%$ de sangre de carnero (Biomerieux), agar chocolate (Biomerieux), caldo cerebro corazón (BHI) y en frasco de hemocultivo (Sistema BacTec, Becton Dickinson). A las 36 h, se obtuvo desarrollo de cocobacilos Gramnegativos en el frasco de hemocultivo inoculado con líquido articular. La identificación como Kingella kingae se realizó por espectrometría de masas con matriz asistida por láser MALDITOF (Brucker) con puntaje 2,14. En los medios de cultivos convencionales, no se obtuvo desarrollo bacteriano. Con los resultados obtenidos, se indicó ampicilina de $400 \mathrm{mg} / \mathrm{kg} /$ día cada 6 h. Se completaron 10 días de tratamiento antibiótico endovenoso y continuó con amoxicilina vía oral de $100 \mathrm{mg} / \mathrm{kg}$ / día hasta completar catorce días más de tratamiento. A los 45 días del diagnóstico, se realizó radiografía control, en la que no se evidenciaron lesiones osteoarticulares, con restauración total de la actividad articular.

\section{DISCUSIÓN}

La patogenia de la enfermedad articular causada por Kingella kingae comienza con la colonización de la faringe posterior tras adherirse la bacteria a la células epiteliales respiratorias. ${ }^{2}$ Puede ingresar al torrente circulatorio y diseminarse en tejidos profundos. K. kingae es un cocobacilo Gram-negativo perteneciente a la familia Neisseriacea. Coloniza el tracto respiratorio superior a nivel amigdalino, condición que favorece su transmisión persona-persona, especialmente entre niños de corta edad con estrecho contacto en guarderías y centros preescolares. ${ }^{3}$ La prevalencia de K. kingae en la faringe de niños sanos de entre 6 y 40 meses es de $10 \%$, del $6 \%$ en niños de mayor edad y nula en menores de 4 meses. Afecta principalmente a niños menores de 5 años y, sobre todo, a menores de dos años, que están protegidos los seis primeros meses de vida por anticuerpos maternos. Este agente etiológico es una causa cada vez más reconocida de la artritis bacteriana, bacteriemia y endocarditis. La incidencia de la enfermedad aumenta en otoño e invierno $y$, con frecuencia, va precedida de una infección del tracto respiratorio superior. ${ }^{4}$ Como lo expresa la bibliografía revisada, nuestro paciente concurre a la guardería y presenta cinco días antes un cuadro de vía aérea superior y posteriormente la afección articular.

La presencia de estomatitis concomitante, en especial gingivoestomatitis herpética, se ha señalado como favorecedora de la penetración del germen, probablemente por aprovechar el efecto inmunosupresor de la infección viral, como así también la lesión de la mucosa. ${ }^{4}$

Este germen es causante de artritis infecciosa, osteomielitis, espondilodiscitis, bacteriemia y endocarditis, especialmente en niños. La infección osteoarticular es la forma más frecuente de presentación $(62,4 \%)$, seguida de bacteriemia sin foco (32\%). La artritis séptica comprende el $80 \%$ de los casos de infección osteoarticular, seguida de la osteomielitis y la espondilodiscitis.

La artritis suele ser monoarticular y afectar articulaciones de carga. Las manifestaciones clínicas habitualmente son inespecíficas, con aumento de los parámetros inflamatorios, y suelen ocurrir con poca afección del estado general. ${ }^{5}$ Este es el caso de nuestro paciente, quien presenta cuadro febril de 48 h de evolución, seguido de compromiso de la articulación de la rodilla derecha, parámetros inflamatorios aumentados en el laboratorio, pero sin afección 
del estado general. Sin embargo, una cuarta parte de los niños pueden presentar registros febriles inferiores a los 38 grados, y un 57\% presenta menos de 15000 leucocitos; un 22\% presenta PCR normal; y un 31\% tiene velocidad de sedimentación globular (VSG) normal.

El aislamiento de Kingella kingae en los medios de cultivo sólidos puede ser difícil. Se ha sugerido que factores indeterminados del líquido sinovial ejercerían un efecto inhibitorio en el crecimiento del germen, por lo que la dilución del líquido sinovial en frascos para hemocultivo puede facilitar el crecimiento e incrementa la recuperación de microorganismos frecuentes y de los fastidiosos. ${ }^{5}$ El uso mejora la tasa de detección en un $63-100 \%$, pero la sensibilidad de este método depende del sistema utilizado. ${ }^{6}$ La fase de bacteriemia transitoria es corta y asintomática, lo que explica la frecuente negatividad de los hemocultivos, como sucedió en nuestro paciente, en el que se halló el agente etiológico mediante la inoculación del material extraído en botellas de hemocultivos, en tan solo $36 \mathrm{~h}$.

Respecto al tratamiento, la mayoría de las cepas aisladas son sensibles a la penicilina, cefalosporina, ciprofloxacina, tetraciclinas y eritromicina, con un 38\% de las bacterias con resistencia a clindamicina. Los antimicrobianos de elección son penicilinas y cefalosporinas. Inicialmente, se recomienda la terapia endovenosa, para luego rotar a vía oral una vez conseguida la mejoría clínica y de parámetros de laboratorio. La duración es discutida entre 14 días y 3 meses para la artritis séptica y de 3 a 6 meses para la osteomielitis. ${ }^{7}$

\section{CONCLUSIÓN}

K. kingae es un patógeno emergente en la infección osteoarticular en pacientes pediátricos, especialmente en niños mayores de 6 meses y menores de 4 años de edad. Teniendo en cuenta su relevancia clínica y el mayor número de casos descritos por la mejoría de métodos diagnósticos microbiológicos, se destaca la necesidad de tener en cuenta este patógeno y de utilizar, en forma rutinaria, frascos de hemocultivo para el procesamiento de las muestras de líquido sinovial.

\section{REFERENCIAS}

1. Otero Reigada MC, Silveira LF, Policarpo SN, Pérez Tamarit MA, et al. Infecciones por Kingella kingae en la edad pediátrica. Enferm Infecc Microbiol Clin 2011;29 Suppl 3:29-32.

2. Kehl-Fie TE, Miller SE, St. Geme JW 3rd. Kingella kingae expresses type IV pili that mediate adherence to respiratory epithelial and synovial cells. J Bacteriol 2008;190(21):7157-63.

3. Slonim A, Walker ES, Mishori E, Porat N, et al. Personto-person transmission of Kingella kingae among day care center attendees. J Infect Dis 1998;178(6):1843-6.

4. Vásquez MA, Palacián MP, Villuendas MC, Marne C, et al. Artritis séptica pediátrica causada por Kingella kingae. Arch Argent Pediatr 2012;110(6):e126-e128.

5. Yagupsky P, Dagan R, Howard CW, Einhorn M, et al. High prevalence of Kingella kingae in joint fluid from children with septic arthritis revealed by the BACTEC blood culture system. J Clin Microbiol 1992;30(5):1278-81.

6. Williams N, Cooper C, Cundy P. Kingella kingae septic arthritis in children: recognising an elusive pathogen. $J$ Child Orthop 2014;8(1):91-5.

7. Yagupsky P. Kingella kingae: from medical rarity to an emerging paediatric pathogen. Lancet Infect Dis 2004;4(6):358-67. 